\title{
Microscopic Lung Airway Abnormality and Pulmonary Vascular Disease Associated with Congenital Systemic-to- Pulmonary Shunt
}

\author{
Hirofumi Sawada, Yoshihide Mitani, Hiroyuki Ohashi, \\ Shoichiro Otsuki, Noriko Yodoya, Hidetoshi Hayakawa, \\ Hironori Oshita, Jane C. Kabwe, Takeshi Konuma, \\ Kyoko Imanaka-Yoshida, Hideto Shimpo, \\ Kazuo Maruyama, and Masahiro Hirayama
}

Keywords

Pulmonary hypertension · Congenital heart disease $\cdot$ Lung biopsy $\cdot$ Pulmonary vascular disease

Links between impaired lung development/growth and pulmonary hypertension (PH) have been demonstrated in infants with bronchopulmonary dysplasia or congenital diaphragmatic hernia. Experimental studies also suggest that a complex interplay of epithelial-endothelial cells is required for normal pre/postnatal lung

\footnotetext{
H. Sawada $(\square)$

Departments of Pediatrics, Mie University School of Medicine, Tsu, Mie, Japan

Department of Anesthesiology and Critical Care Medicine, Mie University School of Medicine, Tsu, Mie, Japan

e-mail: hsawada@clin.medic.mie-u.ac.jp

Y. Mitani $\cdot$ H. Ohashi $\cdot$ S. Otsuki $\cdot$ N. Yodoya $\cdot$ H. Hayakawa $\cdot$ H. Oshita $\cdot$ M. Hirayama Departments of Pediatrics, Mie University School of Medicine, Tsu, Mie, Japan

J. C. Kabwe · K. Maruyama

Department of Anesthesiology and Critical Care Medicine, Mie University School of Medicine, Tsu, Mie, Japan

T. Konuma $\cdot$ H. Shimpo

Department of Thoracic and Cardiovascular Surgery, Mie University School of Medicine,

Tsu, Mie, Japan

K. Imanaka-Yoshida

Department of Pathology, Mie University School of Medicine, Tsu, Mie, Japan
} 
morphogenesis [1]. In this chapter, we focus on the role of lung development/growth abnormality in the development of pulmonary vascular disease (PVD) associated with congenital heart defect (CHD).

Children with large systemic-to-pulmonary shunt typically exhibit symptoms of heart failure in early infancy (tachypnea, failure to thrive), have $\mathrm{PH}$ with increased pulmonary blood flow and do not develop irreversible PVD if closure of defect is performed before 9 months to 2 years of age [2]. In general, the patient's age and type of lesion contribute to the risk of developing irreversible PVD. Conditions with pressure overload and high flow, such as large ventricular septal defect or patent ductus arteriosus, are likely to cause PVD earlier than low-pressure, high-flow lesions (pre-tricuspid shunt such as atrial septal defect). However, we sometimes encounter children with "atypical" $\mathrm{PH}$ which is associated with CHD but unexplained by the type or magnitude of coexisting CHD (e.g., pre-tricuspid shunt or small post-tricuspid shunt with severe $\mathrm{PH}$ and elevated pulmonary vascular resistance [PVR]; large post-tricuspid shunt lacking symptom of heart failure due to high PVR sustained from neonatal period.

Our recent observation suggests that microscopic airway abnormality caused by genetic or pre/postnatal conditions may be associated with PVD in infants with "atypical" PH.

\section{References}

1. Abman SH. Bronchopulmonary dysplasia: "a vascular hypothesis". Am J Respir Crit Care Med. 2001;164:1755-6.

2. Rabinovitch M, Keane JF, Norwood WI, et al. Vascular structure in lung tissue obtained at biopsy correlated with pulmonary hemodynamic findings after repair of congenital heart defects. Circulation. 1984;69:655-67.

Open Access This chapter is licensed under the terms of the Creative Commons Attribution 4.0 International License (http://creativecommons.org/licenses/by/4.0/), which permits use, sharing, adaptation, distribution and reproduction in any medium or format, as long as you give appropriate credit to the original author(s) and the source, provide a link to the Creative Commons license and indicate if changes were made.

The images or other third party material in this chapter are included in the chapter's Creative Commons license, unless indicated otherwise in a credit line to the material. If material is not included in the chapter's Creative Commons license and your intended use is not permitted by statutory regulation or exceeds the permitted use, you will need to obtain permission directly from the copyright holder. 